\title{
Dramatização da aula
}

\section{Resumo}

Iniciando por escrever-se como texto de um pensamento da diferença, pressupõe a pedagogia como uma atividade de criação. Trata-se de texto feito com o método de dramatização de Gilles Deleuze, e que por isso enfatiza o drama e não o logos. E, sendo assim, dramatiza: uma linhagem de educadores, professores, pedagogos que inclui, entre outros, Osman Lins, Roland Barthes, Haroldo de Campos e Paul Valéry; e a aula como espaço-tempo de criação. Deste modo, constitui-se em uma prática de pesquisa contemporânea que assume a dramatização como método.

Palavras-chave: criação, aula, pedagogia, didática, currículo

\section{Dramatization of the class}

\begin{abstract}
Since it starts by writing itself as a text about a thought of difference, it assumes pedagogy as a work of creation. It is a text produced under the Gilles Deleuze's method of dramatization, and, therefore, it emphasizes the drama and not the logos. And, hence, it dramatizes: a lineage of educators, teachers, pedagogues that includes, among others, Osman Lins, Roland Barthes, Haroldo de Campos and Paul Valéry; and the classroom as a space-time setting of creation. Therefore, is it based on a contemporary research practice that takes drama as a method.
\end{abstract}

Keywords: creation, class, pedagogy, didactics, curriculum

\section{Introdução}

Para pesquisar em educação tendo por base uma pedagogia enquanto atividade criadora (OLIVEIRA, 2014), este texto faz uso de três modos de narrar a dramatização da aula como nova possibilidade investigativa.

No primeiro, a variação do tema é que o constitui; porém seu funcionamento é regular, tratando-se de um lugar de divergência, acolhendo notas - principalmente conceituais sobre algo que mereça maior atenção ou minúcia. Tratados como "Tópicos Curriculares", visam dar velocidade a temas que estiverem lentos, servindo ao pensar como uma espécie de mola. A consistência de seus fragmentos é pretensamente explicativa, de 
modo que posso afirmar tais tópicos como referenciais ou enquanto verdadeiros portadores de referência.

No segundo, os fragmentos funcionam como biografemas didáticos, escritos em primeira pessoa, e trazem a dramatização da aula para alguns pedagogos (aqui, professores): ao modo de Paul Valéry e seu "Meu Fausto" (2010), tais pedagogos não representam os papéis que Ihes designo, mas emplois que lhes atribuo de acordo com seu estilo pedagógico.

No terceiro, ao modo de um pintor que, por respeito à cor e ao pintar, dedica-se ao retrato (como um modo prudente de tornar-se atento aos signos ou digno de sua atividade), escrevo retratos pedagógicos de pedagogos, pequenas cenas breves, inflexões de suas aulas (onde, diante de cada retrato, pode-se dizer: há currículo aí). Cada retrato, cada drama da aula escrito afirma textualmente um currículo como "biografema derradeiro" (CORAZZA, 2009, p.46) e pode ser dito pelo burburinho impessoal de um "diz-se" sobre suas aulas.

Com três modos distintos de afirmar a dramatização como prática de pesquisa, seguimos.

\section{Tópicos Curriculares}

1.1 Sobre Ideia. Na distância que a obra de Gilles Deleuze pode percorrer, o conceito de ideia que circula por este texto é pinçado pelo critério de pertinência de uso. Ciente dos abusos, utilizei-o apenas nos domínios alusivos que permitiriam ao leitor facilmente localizá-los. Se há uma enorme distância entre o conceito de ideia que está em "O método de dramatização" (DELEUZE, 2006b) e "Diferença e repetição" (Idem, 2006a) textos de 1967 e 1968, respectivamente - e aquele que circula em "Qu'est ce que l'acte de Création?" (Idem, 1987) e "O que é a filosofia?" (DELEUZE; GUATTARI, 1997c) conferência pronunciada em 1987 e livro publicado em 1991 - ela não foi ignorada, mas observada de modo essencialmente distraído: distração esta, que é a mesma que acompanha a junção entre o método dramático e suas questões genealógicoexperimentais e aquela pergunta que se direciona às atividades de criação (de onde quer?, quando quer?, como quer... - que recusam a pergunta pelo ser - ao disparate alegre que pergunta o que é a filosofia, a arte, a ciência, o cinema? - e ao qual me aproximei ao perguntar o que é a pedagogia, a didática, o currículo?). Se o método de dramatização recusa a questão “o que é...?" por considerá-la índice do logos e via Revista Digital do LAV - Santa Maria - vol. 7, n.2, p. 96-116 - mai./ago.2014 
essencializante, o faz justamente para dizer algo a respeito da ideia - o drama, então, como aquilo que interessa para a aprendizagem da ideia que opera sob um conceito dado na representação (DELEUZE, 2006b). Mas se a questão "o que é...?" retorna e pode alinhar-se ao método dramático é porque ela já trata o "conceito" como algo criado pela filosofia - e não fruto de uma representação da ideia (DELEUZE; GUATTARI, 1997c); e nesse sentido, tal questão não quer dizer mais que: o que é criar em filosofia, em cinema, em pedagogia?

E, enfim, o interesse por criar em uma atividade específica é operado na sintética aproximação (dobra que recusa a distância linear de uma leitura referencial sobre "o conceito", "a ideia" na Obra de um autor): "o que é criar em...?", "o que é...?" (sabendose que a atividade sobre a qual se pergunta é, neste caso, sempre uma atividade de criação), “o que é ter uma ideia em....?" (DELEUZE, 2006a). Utilizando-me, então, da decisão de que ter uma ideia e criar possuem uma aproximação radical e de que uma vez tornadas comuns (como tratar, por exemplo, uma ideia via representação nos termos de um conceito lógico; ou uma noção no campo de uma história de tal atividade - a noção de pedagogia sacralizada em determinado contexto, o entendimento irrecusável sobre didática, a certeza sobre o currículo...) haverá sempre um drama que nos reconduzirá à distinção obscura que pode interessar a novas experimentações (pois experimentar é a maneira de inserir-se em uma atividade de criação, mesmo sem a garantia, pois isso seria um absurdo ingênuo e redutor, de que teremos uma ideia ou criaremos algo naqueles domínios específicos que nos cabem).

1.2 Sobre Criação. Criação não é a resposta inovadora a um problema dado. De modo algum o texto visa uma pedagogia atenta à criatividade. Criar funciona aqui como a invenção de novos problemas, "não a saída de um problema justo, justo um problema" (CORAZZA, 2010c). Criar é ter uma ideia em um domínio específico, com suas contingências e possibilidades de expressão. Não se cria uma solução, por certo; como não se cria algo geral, de extensão global; têm-se uma ideia com o alcance da necessidade do problema que ela coloca - e com a névoa ou repertório de soluções já apresentadas em determinado domínio: é nessa direção que se pode dizer que se cria, necessariamente, algo novo: “os problemas são as próprias Idéias" (DELEUZE, 2006a, p.233). Se nominamos, por sua vez, um criador - com base na atividade de criação que exerce: o pedagogo, o artista, o cientista, o filósofo - renegamos qualquer possibilidade de instituição ou culto de gênios: criar só é possível na impessoalidade ou suspensão da grosseira expressão daquele que cria - por isso, qualquer denominação ou nome próprio 
que atribuímos a um criador não é nada mais que a instituição de uma nova criatura que pensa o pensamento para fins de uma experimentação que estamos operando.

1.3 Sobre Pensamento. "É no pensar que está implicada a criação, a gênese do ato de pensar no próprio pensamento" (HEUSER, 2010, p. 119), onde quem o habita é necessariamente um acéfalo: dado que para Gilles pensar é criar, o próprio pensamento não pode ser considerado como um objeto passível de aquisição ou como natureza a ser exercida; "trata-se de produzir o ato de pensar no próprio pensamento" (Ibidem, p.81)... Por certo a inoculação da serpente valéryana em Gilles, produzindo uma espécie rara de mutação do pensamento, o qual só pode ser lido com um "Método Valéry-Deleuze" (CORAZZA, 2010b; 2010c; 2011a; 2011b).

1.4 Sobre Plano. "Plano monstruoso" (ZORDAN, 2004, p.102), um texto é feito de muitos planos. A execução deste demandou uma série deles. O primeiro poderia ser dito como um "plano geo-educacional [...] que comporta uma pedagogia do espaço liso, que se encontra fora das imagens de pensamento das quais a educação costuma dispor." (Ibidem, p.109). Plano mirabolante de encaixes e desencaixes, alusões alucinatórias e ilusões comuns, curvaturas variáveis. Por certo toda atividade de criação possui seu plano específico; e neste caso o plano próprio à pedagogia não podia abster-se de jogar com as imagens mais comuns de plano de ensino, plano de aula ou plano pedagógico. Mas o plano, neste texto, "envolve movimentos infinitos que o percorrem e retornam" (DELEUZE; GUATTARI, 1997c, p. 51), imagem do deslocamento tipicamente pedagógico. No caso da filosofia, os "conceitos são o arquipélago ou a ossatura, antes uma coluna vertebral que um crânio, enquanto o plano é a respiração que banha essas tribos isoladas." (Ibidem, p.52). Mesmo na pedagogia, "o plano é o absoluto ilimitado, informe, nem superfície nem volume, mas sempre fractal", "máquina abstrata" e "horizonte dos acontecimentos" didáticos. Se o "plano é como um deserto", que "não tem outras regiões senão as tribos que o povoam e nele se deslocam" (I bidem, p.52-53), a pedagogia passa a dispor de um bando de pedagogos que assaltam e roubam as diligências de certos professores, cujos "nomes próprios aos quais se vincula assim a enunciação, malgrado serem históricos, e atestados como tais, são máscaras para outros devires, servem somente de pseudônimos a entidades singulares mais secretas" (I bidem, p.36). 
1.5 Sobre Acontecimento. A didática diz o acontecimento da aula e não uma prática de fatos, não uma teoria sobre a aula ou generalizações extraídas de certa materialidade extensa. Por isso, podemos dizer "a didática de Valéry", "a didática de Wladimir" como se disséssemos: "o acontecimento pedagógico de Gilles", "o acontecimento pedagógico de Roland"... Isso ou "o pássaro como acontecimento" (DELEUZE; GUATTARI, 1997, p.33).

1.6 Sobre Atual e Virtual. Em estado de suspensão ou deslocamento perpétuo, a pedagogia está imersa em uma atmosfera das multiplicidades. Para os fins e usos deste texto, onde o currículo é o libreto da atualização de uma criação em pedagogia, o atual nunca pode ser entendido enquanto objeto puro, plenamente realizado, mas deve ser lido em virtude da dramaticidade dos dinamismos. "Todo atual rodeia-se com uma névoa de imagens virtuais", de modo que "uma partícula atual emite e absorve virtuais mais ou menos próximos, de diferentes ordens" (DELEUZE, 1996, p. 49). O plano pedagógico envolve tanto a força virtual de uma didática quanto sua atualização em currículos, visto que o "atual é o complemento ou o produto, o objeto da atualização, mas esta não tem por sujeito senão o virtual", e que a "atualização do virtual é a singularidade, ao passo que o próprio atual é a individualidade constituída" (Ibidem, p.51).

Mas como podemos ver com o drama do Currículo de Licenciatura em Pedagogia, sempre há trocas "entre o objeto atual e sua imagem virtual", de modo que atual e virtual "coexistem, e entram num estreito circuito que nos reconduz constantemente de um ao outro" (Ibidem, p.53-54). Deste modo, a dramatização de tal Currículo só é possível por investir tanto no atual quanto no virtual (sendo este efêmero, visto que sua criação e destruição são mais rápidas que um tempo extenso pensável), uma vez que a relação que se estabeleceria entre dois atuais seria de outra ordem (de modo grosseiro, acabaria redundando em simples comparação, no caso que nos cabe). "Os atuais implicam indivíduos já constituídos, e determinações por pontos ordinários", e por isso, por si só, não bastariam para uma dramatização que pressupõe atores informes; "ao passo que a relação entre o atual e o virtual forma uma individuação em ato ou uma singularização por pontos relevantes a serem determinados em cada caso" (Ibidem, p.56). "A diferença entre virtual e atual já não é a do Mesmo enquanto situado uma vez na representação e outra vez fora da representação, mas é a do Outro enquanto aparece uma vez na Ideia e outra vez, de modo totalmente diferente, no processo de atualização da Ideia" (Idem, 2006b, p.137). 
1.7 Sobre Diferençação e diferenciação. A relação entre atual e virtual só pode ser escrita com o método de dramatização e sua noção complexa de diferen(ci/ç)ação différen(t/c)iation (DELEUZE, 1996; 2005a; 2006b; TADEU, 2005) é ela que mostrará o funcionamento de uma individuação em ato e as operações de singularização por pontos relevantes. Dentre as propriedades dos dinamismos espaço-temporais está a de determinar as qualidades e extensões, bem como as espécies e partes da diferençação; diferençar-se é o mesmo que atualizar-se para uma Ideia - de modo que ela é distinta ou diferenciada nela mesma (como um sistema de relações diferenciais) antes de atualizar-se ou de se diferençar no atual: o que lhe confere a obscuridade ante a clareza de uma ideia passível de representação. “Devemos sublinhar, entretanto, a condição absoluta de não-semelhança: a espécie ou a qualidade não se assemelha às relações diferenciais que elas encarnam, do mesmo modo que as singularidades não se assemelham ao extenso organizado que as atualiza" (DELEUZE, 2006b, p.136), uma vez que a Ideia - ligada ao criar - é sempre distinta ou diferenciada e obscura ou indiferençada. Por sua vez, não um universal, mas um fundo pré-individual que é exprimido via diferenciação - fundo distinto-obscuro que é o drama sob todo logos.

1.8 Sobre Método de dramatização. Dado um currículo, ou assinada uma didática, é preciso pesquisar o drama que lhe corresponde. Se the interessa determinar algo sobre a ideia, o pensamento, a criação, o método de dramatização poderá ser empregado. De modo mais purista, mas pouco afeito à própria espira na qual se encontra, o método pode ser tomado em "Nietzsche e a filosofia", em "Diferença e repetição" e na conferência "O método de dramatização" (DELEUZE, 1976; 2006a; 2006b). Apesar da distância cronológica e referencial no que diz respeito a uma organização da Obra deleuziana, "Sobre o teatro" (DELEUZE, 2010c) cria a possibilidade alusiva e textual de tornar a pesquisa via o método de dramatização mais próxima a sua postulação: o teatro lido por Deleuze pode afigurar o próprio teatro dramático de uma pesquisa. "Mil Platôs" (DELEUZE; GUATTARI, 1995a; 1995b; 1996; 1997a; 1997b) é inçado de passagens que poderiam ser ditas exemplares de uma dramatização. Porém, todos aqueles textos, sejam eles quais forem, que não escamoteiam sua condição de texto podem servir de atores neste teatro cruel. A questão é saber tomar o método de dramatização - escrito e pensado com a execução da atividade filosófica - como princípio a ser rasurado, reescrito, reimaginado, com outros dramas próprios à atividade de criação e domínios que Ihe cabem - é o que faz, por exemplo, Corazza (2010b; 2011; 2012a), sulcando o método de dramatização com a comédia intelectual de Valéry e a possibilidade de pesquisar os dramas curriculares da educação. 
1.8 Sobre Estilo. Avaria o belo da língua via um processo de variação contínua. Estranha e arranha a superfície mais agradável. Unhas no quadro. Pode ser estilo. “O estilo está, em Deleuze, muito mais ligado à política do que à estética. Ele serve para submeter a língua a um processo de variação contínua com vistas a transformar quem escreve e quem lê" (TADEU, 2004, p.170). Um pedagogo que se encontra com mil costas à multiplicidade, no processo de criação de didáticas, possui um estilo. Todo aquele capaz de assinar uma criação enquanto acontecimento em sua atividade e domínios é um estilista.

Tomaz (TADEU, 2004) expõe a lista da estilística de Gilles, bem como aquilo que Deleuze tratou por estilo; o próprio barroco (DELEUZE, 1991) pode ser dito como um estilo particular. E nesse sentido, a marca que distingue uma criação pedagógica de outra criação pedagógica é sempre o rastro dramático do estilo, o modo de relação com a multiplicidade. Didática da transcriação. Didática neobarroca. Pedagogia escritural. E os múltiplos dramas da aula que fazem do nome de um professor a assinatura de uma criação em pedagogia. O estilo, aqui, não renega qualquer forma de experimentação na língua: nem recursos tipográficos, nem astúcias lexicais, tampouco a mistura de palavras e audácias sintáticas: nesse ponto uma desavença com o professor Gilles e suas preferências. Mas também, o estilo não clama por saídas de vanguardistas e pelo experimentalismo débil. A variação imposta por um estilo à língua é tão mais radical quanto estiver impregnada do problema que está envolvido em sua atividade de criação. E para isso, toda a mistura (ou pureza) necessária: existem domínios de criação específicos, porém a força e a estranheza de um drama sempre pode arrastar partículas virtuais plenamente díspares para um domínio outro. "Encontro-me no meio [...] sempre gostei de perseguir minha sombra e nela desaparecer" (MUNHOZ, 2009, p.18); eis a posição de um estilista.

1.9 Sobre Diferença e repetição. Não há referência mais evidente que "Diferença e repetição" (DELEUZE, 2006a) para este tópico - dele poderemos partir para outras ilhas como "Nietzsche e a filosofia" (Idem, 1976). No interesse específico deste texto, é o processo de diferenciação que está no cerne da produção do novo e da criação em cada domínio. A diferença, por sua vez, é aquilo que "age duplamente: no interior da multiplicidade e em direção ao seu exterior" (TADEU, 2004, p.139). Mas é a repetição do processo de diferenciação que garante a o movimento da diferença, seu retorno 
incessante e radical: repetição não do produto da criação (e o que isso importaria?), mas do instante produtor do novo.

1.10 Sobre Simulacro. A definição de Feil para simulacro poderia compor toda a extensão deste tópico: "Instância que abole toda possibilidade de haver um original" (2010, p.86). Porém, de modo indiciário, prefiro colecionar mais algumas passagens elucidativas e atraentes. Primeiro, dizer que o “simulacro não é uma cópia degradada, ele encerra uma potência positiva que nega tanto o original como a cópia, tanto o modelo como a reprodução" (DELEUZE, 2007, p.267) - a monstruosidade de algumas passagens vertidas via transcriação, ou mesmo acoplagens que inventam uma reciprocidade teórica entre formulações distantes marcam bem a potência positiva do simulacro nesta pesquisa. Segundo, que modelo algum é capaz de resistir "à vertigem do simulacro" (Ibidem, p.267-268), onde nenhuma hierarquia é possível e onde a "semelhança subsiste, mas é produzida como efeito exterior do simulacro, na medida em que se constrói sobre as séries divergentes e faz com que ressoem" (Ibidem, p.268) - ressonância que pode ser dita como a marcha dos pedagogos larvares que circulam de um fragmento a outro do texto, que deslocam toda definição possível a cada nova aparição, a cada espira, a cada quadrícula temática que se abre e encerra, mas não sem antes trair-se e dizer de uma condução textual ambígua.

1.11 Sobre Neobarroco. A incompossibilidade da condução e da não-condução, paradoxo pedagógico, é a condição de produção de uma didática neobarroca.

\section{Retratos pedagógicos}

2.10 professor Gilles repetia sempre suas aulas. Apressado após repetir sua preparação para a aula à exaustão, o professor Gilles arrancava as folhas dos livros que guardavam os fragmentos que Ihe interessavam - um modo prático para, na aula, não carregar nada além do necessário. O fragmento notável, após o uso, perdia-se - sendo impossível repetir aquilo que disparou a preparação para a aula, sendo impossível repetir o livro que Ihe havia servido enquanto intercessor. Sem saída, o professor Gilles repetia sempre suas aulas: uma longa preparação, alguns fragmentos arrancados... 
2.2 0 professor Bob organizava suas aulas em um saco. Aos sustos se iniciavam as aulas do professor Bob; figura arranjada, com uma espécie de arte do detalhe - sem, no entanto, fornecer a certeza de sua organização - onde tudo era nitidamente preparado, mas cuja execução parecia improvisada: o saco de algodão cru onde o professor Bob carregava sua aula era digno de nota: lá estava tudo aquilo que era necessário, sendo que ao longo das horas um ou outro fragmento era de lá retirado: uma pequena vassoura, uma máscara de palhaço, um axioma, um tratado, uma história breve, uma pequena máquina de escrever, uma harmônica ordinária... O saque, no entanto, não obedecia a nenhuma regulação e aquilo que de lá era retirado não sofria julgamento: sacar, com o Professor Bob, era o mesmo que achar, encontrar - e com isso seguir. Assim organizada, sua aula não era - nem por ele - reconhecida; porém, executada, arranjada, improvisada com um saco especialmente preparado: a cada vez.

2.3 o professor Dante não nutria esperança em suas aulas. Do professor Dante pouco posso dizer. Parecia não ser de esquerda, mas pouco crente também para o outro lado. Diziam que chegava cedo, sempre estava lá, sentado em sua mesa lendo e à espera do início da aula. Na porta de entrada, escrito no chão com giz branco, porém em tom escuro, a mesma frase de sempre: “Deixai toda esperança, ó vós que entrais." Não se sabe se o professor Dante era quem escrevia a advertência. Por mais cedo que se chegasse ele e a frase já estavam lá. Mas de tudo isso pouco posso dizer.

2.4 A professora Sandra com ar de Dylan e o seu objeto de aprendizagem. Algumas vezes havia certa desconfiança de que aquilo que a professora Sandra dizia pouco serviria para o "chão da escola". Fingindo não se importar, mesmo sendo hábil indutora de novas aulas, a professora Sandra, com uma calça de couro preta, unhas finas e longas e com um ar do jovem Dylan e suas sacadas gaiatas sorriu, cortou tal riso, arqueou o corpo para frente, cotovelos na mesa, jogou os pés cruzados para trás da cadeira e alfinetou: vejam, um saco é o único objeto de aprendizagem que me cabe. Dedos de alfinetes. E seus pequenos pés no chão da escola.

2.50 professor Roland e o prazer da aula. Atento aos que Ihe rodeavam, ele desviou o olhar ao ver que havia um livro riscado na mesa de um dos seus melhores alunos. $O$ PRAZER DO TEXTO agora era DA AULA. Após a aula, desta vez com um cigarro Revista Digital do LAV - Santa Maria - vol. 7, n.2, p. 96-116 - mai./ago.2014 
americano, não deixou de dizer - com certo charme característico: "A aula de prazer é Babel feliz".

2.6 O professor Enrique e a Pedagogia Portátil. Mestre da cátedra de Pedagogia Portátil, o professor Enrique possuía um axioma que dizia de seu estilo pedagógico:

\author{
A aula deve caber em um bolso \\ e o seminário em uma valise.
}

2.7 Veloz, o professor Wladimir escrevia suas aulas. Havia nas aulas do professor Wladimir um paradoxo. Dançarino, seus movimentos eram lentos e fortes, ordenados pela pilha de livros e citações que ficavam ao seu lado direito. Precavendo-se ao máximo com uma metalinguagem, a fala do professor Wladimir era essencialmente poesia. E isso deixava alguns alunos confusos, mesmo se encantados. Escrevendo no ar, com as mãos repousadas na mesa, as palavras lentas e fortes, eram suspensas por uma velocidade própria. Três horas escrevendo a aula com quem se dispusesse a lê-la. Definitivamente, o professor Wladimir era muito veloz.

2.8 O professor Paulo carregava Cartesius para os trópicos de sua aula. O professor Paulo era conhecido por sua repugnatio benevolentiae. Em suas aulas se negava a ministrar clareiras à inteligência. A inteligência, ele pensava, passou até aqui muito bem sem mapas. No entanto, suas aulas eram incansáveis em fornecer descoordenadas da artesania de sua própria inteligência. Era aí que a cobra mordia o próprio rabo.

2.9 O professor Roland e a elegância de seus pseudônimos. Havia nas aulas do professor Roland tamanha elegância ao falar sobre si que ao sair de sua aula não parava de anotar detalhes e pormenores de outros professores. O professor Roland possuía muitos nomes para tratar de sua fantasia como sendo a fantasia de muitos outros. Ao final de uma de suas aulas, anotei: "seria possível falar de um professor com tal rigor e proximidade que pudesse atribuir-Ihe o meu próprio nome?". 
2.100 professor Arturo era especialista na arte de fracassar em aula. Bandini, eu me chamo Arturo Bandini. Era assim que iniciavam as aulas do professor Arturo, sempre versando o fracasso.

2.11 O professor Tomaz e as lições do teatro portátil. O silêncio nas aulas de poética obedeciam a uma métrica exemplar de variação. Sentado em sua mesa, bloco e caneta alinhados e diminutos, relógio de bolso sobre a mesa, uma folha para leitura, calças azulmarinho e camiseta branca, suspensórios e All Star. Raramente se levantava e escrevia um exemplo no quadro - que ficava um pouco mais alto que o seu lugar habitual na sala. Mesmo imóvel, com o auxílio de seus objetos portáteis, parecia sempre querer sair o mais rápido possível. Porém, de modo elegante. Ao tratar da poética de Mallarmé, o professor Tomaz escrevia-se - como se o fizesse sobre o teatro.

2.12 O professor Gonçalo não lidava bem com perguntas verdadeiras. Há muito não sabiam dizer de suas aulas. Parece que ocorriam em círculos restritos. Nunca se sabe. Talvez apenas um burburinho para justificar, sem amolações, a sua longa parada. De toda sorte, tudo parece ter começado com uma pergunta simples escrita por um aluno em sua prova. Era uma espécie de devolução da incapacidade produzida pelas longas aulas sobre o hábito de falsear. Como falsear o falso? Esta única questão foi capaz de paralisar as aulas do professor Gonçalo.

2.13 O professor Jorge era um exímio pensador de saídas. Enquanto na sala de aula entravam os alunos, o professor Jorge só pensava na saída: se só havia uma, era melhor não tê-los deixado entrar. Portanto, a cada semana, um aluno era escolhido para fazer as vezes de desinteressado. Quinze minutos e pronto. Sem cerimônias, sua função era a de deixar o professor Jorge falando, não importando se aquilo que dizia the interessava ou não. Um a um os alunos deixavam a sala. Ao final de algumas horas o professor Jorge já se sentia mais tranquilo. Sua saída fora garantida pela fala. Talvez agora pudesse vir a escrever. Mas logo o último aluno saía e o professor pensava que havia perdido demasiado tempo. Melhor seria contratar um ator italiano, talvez argentino ou francês, que se dispusesse a encenar seu papel todas as semanas. Distraído por quase encontrar uma outra saída, e um tanto confuso com seu sotaque, o professor Jorge quase não percebia que o primeiro aluno já cruzava a porta da sala de aula. 
2.140 professor Stephen não perdia a rua de vista durante suas aulas. O professor Stephen, tendo trocado de lugar sua aula, aproveita para, antes de ir, reler um antigo comentário - sem deixar de impor, nesta nova leitura, toda a distração de quem já sabe o que encontrará, em lancinantes cortes horizontais de olhos rápidos; a nova localização, a proximidade da rua, o teto indeciso, a fatia de pão no estômago, o café parco esfriando na xícara grande compõem aquilo que ele jamais diria - jamais diria exatamente nestes termos.

2.15 Para o professor Charles ela sempre estava na aula ao lado. O professor Charles sentia a tensão da cena que o rodeava. Ela estava na aula ao lado. Uma porta, um corredor, outra porta. Os pés do senhor Charles batiam num alternar nervoso no assoalho de madeira. Ela estava na aula ao lado. Não havia mais nada a fazer. Os pés do senhor Charles ainda batiam num alternar nervoso no chão de tacos de madeira. Certamente, pela tensão da cena que o rodeava, as duas portas e o corredor, ela ainda estava na aula ao lado.

2.16 A valise cinza do professor John e o figurino da aula. O professor John era das figuras mais elegantes, e não existiria parca remuneração que o obrigasse a trocar algumas roupas no brechó, seguidamente. Mas o professor John o fazia, seguidamente. As roupas eram escolhidas desconsiderando seus cortes, cores e tecidos. Tenho minha própria tendência, dizia o professor. Não havia descuido, porém, ao verificar, no bordado da etiqueta interna de cada peça, qual o nome do antigo proprietário daquelas vestes. Professor... ah, sim. Serve-me. Mesmo estando com sapatos trocados e desajeitado como equilibrista, o professor J ohn era uma das figuras mais elegantes. O professor John e sua valise cinza.

2.17 Apologista do texto, o professor Haroldo escrevia uma Didática Neobarroca. Implicado em fazer de sua aula um Laboratório de Textos que experimentasse objetos de aprendizagem, o professor Haroldo praticava aquilo que dizia ser uma Didática da Transcriação via o trabalho concentrado em duas frases que traduziam a mesma passagem de um texto:

“- Seu sabe-tudo, seu miserável velho pedagogo - disse o editor em resposta." (JOYCE, 2007, p.162). 
“- Vaitecatar, seu pedagogo do demônio! o editor disse em sinal de reconhecimento." (Idem, 2012, p.260).

Com a barba a sorrir, o professor Haroldo seguia sua aula. E não seria este um exemplo concreto de que toda Didática da Transcriação é, potencialmente, uma Didática Neobarroca? Mil pedagogos na aula - "vaitecatar"!

\section{O Drama da Aula}

3.1 Osman Lins, Estudo da Aula I. Exerço sobre a construção da aula um rigor só concedido a algumas formas poéticas.

3.2 Osman Lins, Estudo da Aula II. Sobre um rigor de construção da aula, assenta a nota de uma ordem no mundo - ou de uma abertura a ser produzida.

3.3 Osman Lins, Estudo da Aula III. Construo a aula com rigor, para introduzir nela aquilo que é inerente à vida: o princípio de imprevisto e aleatório.

3.4 Gilles Deleuze, Estudo da Aula I. Carrego somente os fragmentos necessários para retornar à aula (e ao livro) em outro lugar.

3.5 Gilles Deleuze, Estudo da Aula II. Crio, ou tento criar, a aula como um espaço-tempo especial.

3.6 Gilles Deleuze, Estudo da Aula III. Repito uma longa preparação para executar poucos instantes de uma aula. 
3.7 Gilles Deleuze, Estudo da Aula IV. Executo uma aula pois tenho dela uma verdadeira noção musical. E boa ou má, não interrompemos a execução de uma música...

3.8 Gilles Deleuze, Estudo da Aula V. Preparo uma aula na solidão absoluta - ao ponto dela ser extremamente povoada de encontros. É do fundo dessa solidão que crio uma aula.

3.9 Gilles Deleuze, Estudo da Aula VI. Para uma aula carrego apenas um saco, onde coloco tudo o que encontro. Nela, interessa-me apenas que me coloquem, também, em um saco.

3.10 Paul Valéry, Estudo da Aula I. Para dar uma aula, mordo aquilo que posso.

3.11 Paul Valéry, Estudo da Aula II. Em aula, pedagogo me dizem - mas eu não compreendo.

3.12 Paul Valéry, Estudo da Aula III. Minhas aulas são meu vício; trato-as como contraacabadas. Minhas aulas, contraobras.

3.13 Paul Valéry, Estudo da Aula IV. Sou um pedagogo que as boas aulas sobre Pedagogia pouco interessa e que as coisas reputadas "pedagógicas" por vezes entedia. Testo minhas aulas com este tédio e interesse.

3.14 Paul Valéry, Estudo da Aula V. Testo uma aula precavendo-me a garantir o máximo de imprevisibilidade durante o teste. Para a aula, como para o pensamento, o imprevisto é o mais fecundo. Por isso, preparo-o.

3.15 Paulo Leminski, Estudo da Aula I. Uma aula é um romance-ideia por onde circula um monstro puramente semiótico.

Revista Digital do LAV - Santa Maria - vol. 7, n.2, p. 96-116 - mai./ago.2014 
3.16 Roland Barthes, Estudo da Aula I. Escrevo minhas aulas para que enquanto operador de linguagem eu funcione mais como escritor do que intelectual ou professor: esperam que eu fale, fantasio que escrevo.

3.17 Roland Barthes, Estudo da Aula II. Que eu e o professor Gilles tenhamos uma predileção por Schumann não é espantoso. Na aula, tanto um quanto outro fazemos com que o texto lido só possa ter sido escrito para aquele que o lê: o verdadeiro pedagogo amador, sou eu.

3.18 Roland Barthes, Estudo da Aula III. A aula, diferentemente da conferência, é o espaço paciente onde nada precisa ser combatido: apenas desorientado. Ao falar, na aula, posso executar a escritura de forma amadora - como se estivesse em uma execução privada. É meu corpo de pedagogo que está na aula, mas a flutuar.

3.19 Haroldo de Campos, Estudo da Aula I. A inconveniência da escritura está em minha aula como poesia que racha, feito erva daninha no concreto da fachada, a prosa científica da boa porque velha aula museológica.

3.20 Haroldo de Campos, Estudo da Aula II. A fisicalidade de minha aula está no texto. Só posso ser um professor concreto.

3.21 Haroldo de Campos, Estudo da Aula III. Por não diferir aquilo de que uma aula trata e o trato da língua nesta mesma aula pratico, na radicalidade pedagógica de um ensino transcriador, uma operação textual que inventa - aula e texto, portanto - objetos de aprendizagem múltiplos: no barrocolúdio da aula um pedagogo barrocolúdico: neobarrocodelia didática.

3.22 J ohn Fante, Estudo da Aula I. A caminho estou. A aula sempre começa por algum lugar. 


\section{Conclusão}

A pedagogia como atividade de criação possibilita uma pesquisa em educação via método de dramatização. Tal método, por sua vez, implica novos modos de escrever uma investigação. A pesquisa, então, pode ser dita como uma prática dramática.

\section{Referências}

ADÓ, Máximo Daniel Lamela. Educação Potencial: autocomédia do intelecto. Porto Alegre, 2013. Tese (Doutorado em Educação). Programa de Pós-Graduação em Educação, Faculdade de Educação, Universidade Federal do Rio Grande do Sul, Porto Alegre, 2013. Disponível em <http://hdl. handle.net/10183/69921>.

ADÓ, Máximo Daniel Lamela. Comédia Intelectual da Educação. Porto Alegre, 2010. Projeto de Tese (Doutorado em Educação). Programa de Pós-Graduação em Educação, Faculdade de Educação, Universidade Federal do Rio Grande do Sul, Porto Alegre, 2010a. ADÓ, Máximo Daniel Lamela. O currículo de areia. In: CORAZZA, S. M. (Org.). Fantasias de escritura: filosofia, educação, literatura. Porto Alegre: Sulina, 2010b, p. 131-141.

ALIGHIERI, Dante. A Divina Comédia. Tradução de Italo Eugenio Mauro. São Paulo: Ed. 34, 2009.

BARTHES, Roland. Amar Schumann. In: BARTHES, R. O óbvio e o obtuso. Tradução de Isabel Pascoal. Lisboa: Edições 70, 2009a, p.281-286.

BARTHES, Roland. Aula. 13. ed. Tradução de Leyla Perrone-Moisés. São Paulo: Cultrix, 2007.

BARTHES, Roland. A música, a voz, a língua. In: BARTHES, R. O óbvio e o obtuso. Tradução de Isabel Pascoal. Lisboa: Edições 70, 2009b, p.265-271.

BARTHES, Roland. Música Práctica. In: BARTHES, R. O óbvio e o obtuso. Tradução de Isabel Pascoal. Lisboa: Edições 70, 2009c, p.249-253. 
BARTHES, Roland. O prazer do texto. Tradução de J. Guinsburg. São Paulo: Perspectiva, 2006.

BORGES, Jorge Luis. Ficções. Tradução de José Colaço Barreiros. Lisboa: Teorema, 2009.

CALVINO, Italo. Seis propostas para o próximo milênio: lições americanas. Tradução de Ivo Barroso. São Paulo: Companhia das Letras, 1990.

CAMPOS, Augusto de. Paul Valéry: a serpente e o pensar. 2. ed. São Paulo: Ficções, 2011.

CORAZZA, Sandra Mara. O drama do currículo: pesquisa e vitalismo de criação. In: IX

ANPED SUL. 2012a. Disponível em:

<http://www.ucs. br/etc/conferencias/index.php/anpedsul/9anpedsul/paper/viewFile/ 128 /786>.

CORAZZA, Sandra Mara. Dramatização do infantil na comédia intelectual do currículo: método Valéry-Deleuze. Projeto de Pesquisa e Plano de Trabalho; Bolsa de produtividade em pesquisa - CNPq. Texto digitado. 2011 .

CORAZZA, Sandra Mara. Notas. In: HEUSER, E. M. D. (Org.). Cadernos de Notas I: projeto, notas \& ressonâncias. Cuiabá: EdUFMT, 2011b, p. 31-96.

CORAZZA, Sandra Mara. Seminário Avançado: O método de dramatização na comédia do intelecto: Valéry \& Deleuze. Seminário Avançado realizado junto ao Programa de PósGraduação em Educação da Universidade Federal do Rio Grande do Sul no primeiro semestre de 2010. Porto Alegre, 2010b. Anotações do Seminário.

CORAZZA, Sandra Mara. Seminário Avançado: O que é o ato de criação? Método Valéry-Deleuze. Seminário Avançado realizado junto ao Programa de Pós-Graduação em Educação da Universidade Federal do Rio Grande do Sul no segundo semestre de 2010. Porto Alegre, 2010c. Anotações do Seminário.

CORAZZA, Sandra Mara. Currículo. In: AQUINO, J.G.; CORAZZA, S.M. (Orgs.). Abecedário: educação da diferença. Campinas: Papirus, 2009, p. 40-46.

CORAZZA, Sandra Mara; AQUINO, Julio Groppa. (Orgs.). Dicionário das ideias feitas em Educação. Belo Horizonte: Autêntica Editora, 2011.

DELEUZE, Gilles. O atual e o virtual. In: ALLIEZ, É. Deleuze filosofia virtual. Tradução de Heloisa B. S. Rocha. São Paulo: Ed. 34, 1996, p.47-57. 
DELEUZE, Gilles. Crítica e clínica. Tradução de Peter Pál Pelbart. São Paulo: Ed. 34, 1997.

DELEUZE, Gilles. Diferença e repetição. Tradução de Luiz Orlandi e Roberto Machado. Rio de Janeiro: Graal, 2006a.

DELEUZE, Gilles. Différence et répétition. Paris: Presses Universitaires de France, 2005a.

DELEUZE, Gilles. A Dobra: Leibniz e o barroco. Tradução de Luiz B. L. Orlandi. São Paulo: Papirus, 1991.

DELEUZE, Gilles. Lógica do Sentido. Tradução de Luiz Roberto Salinas Fortes. São Paulo: Perspectiva, 2007.

DELEUZE, Gilles. O Método de dramatização. In: A ilha deserta: e outros textos. Org. e revisão técnica da edição brasileira de Luiz B. L. Orlandi. São Paulo: Iluminuras, 2006b.

DELEUZE, Gilles. Nietzsche e a filosofia. Tradução de Edmundo Fernandes Dias e Ruth J offily Dias. Rio de Janeiro: Editora Rio, 1976.

DELEUZE, Gilles. Qu'est ce que l'acte de Création? - Conférence donné dans le cadre dês "Mardis de la Fondation ", le 17 mars 1987. Vídeo disponível em <youtube.com/watch?v=oAH6wLW6W2k>, acessado em 16/06/09, às $13 \mathrm{~h}$.

DELEUZE, Gilles. Sobre o teatro: Um manifesto de menos; O esgotado. Tradução de Fátima Saadi, Ovídio de Abreu, Roberto Machado. Rio de Janeiro: Jorge Zahar Ed., 2010c.

DELEUZE, Gilles; GUATTARI, Félix. Mil Platôs: Capitalismo e esquizofrenia. Tradução de Aurélio Guerra Neto e Célia Pinto Costa. Rio de Janeiro: Ed. 34, 1995a. V. 1.

DELEUZE, Gilles; GuATTARI, Félix. Mil Platôs: capitalismo e esquizofrenia. Tradução de Ana Lúcia de Oliveira e Lúcia Cláudia Leão. São Paulo: Editora 34, 1995b. V. 2.

DELEUZE, Gilles; GuATTARI, Félix. Mil Platôs: capitalismo e esquizofrenia. Tradução de Aurélio Guerra Neto, Ana Lúcia de Oliveira, Lúcia Cláudia Leão e Suely Rolnik. São Paulo: Editora 34, 1996. V. 3.

DELEUZE, Gilles; GUATTARI, Félix. Mil Platôs: capitalismo e esquizofrenia. Tradução de Suely Rolnik. São Paulo: Editora 34, 1997a. V. 4. 
DELEUZE, Gilles; GuATTARI, Félix. Mil Platôs: capitalismo e esquizofrenia. Tradução de Peter Pál Pelbart e Janice Caiafa. São Paulo: Editora 34, 1997b. V. 5.

DELEUZE, Gilles; GUATTARI, Félix. O que é a filosofia? Tradução de Bento Prado Jr. e Alberto Alonso Muñoz. Rio de Janeiro: Ed. 34, 1997c. 2a Edição.

FANTE, John. Sonhos de Bunker Hill. Tradução de Lúcia Brito. Porto Alegre: L\&PM, 2003.

FEIL, Gabriel Sausen. O simulacro e o biografema - de A a Z. In.: CORAZZA, S.M. (Org.). Fantasias de escritura: filosofia, educação, literatura. Porto Alegre: Sulina, 2010, p. 79-91.

GARCIA, Wladimir. Seminário Avançado: Roland Barthes e a Educação: cenas de escritura. Seminário Avançado realizado junto ao Programa de Pós-Graduação em Educação da Universidade Federal do Rio Grande do Sul no segundo semestre de 2011. Porto Alegre, 2011. Anotações do Seminário.

HEUSER, Ester Maria Dreher. Pensar em Deleuze: violência e empirismo no ensino de filosofia. Ijuí: Ed. Unijuí, 2010.

JOYCE, James. Ulisses. Tradução de Bernardina da Silveira Pinheiro. Rio de Janeiro: Objetiva, 2007.

JOYCE, James. Ulysses. Tradução de Caetano W. Galindo. São Paulo: Penguin Classics Companhia das Letras, 2012.

LEMINSKI, Paulo. Catatau: um romance-ideia. São Paulo: Iluminuras, 2011.

LINS, Osman. Avalovara. São Paulo: Companhia das Letras, 2005.

MUNHOZ, Angélica Vier. Coreogeografias. Porto Alegre, 2009. Tese (Doutorado em Educação). Programa de Pós-Graduação em Educação, Faculdade de Educação, Universidade Federal do Rio Grande do Sul, Porto Alegre, 2009. Disponível em < http://hdl.handle.net/10183/18254 >.

OLIVEIRA, Marcos da Rocha. Biografemática do homo quotidianus: O Senhor Educador. Porto Alegre, 2010. Dissertação (Mestrado em Educação) - Programa de PósGraduação em Educação, Faculdade de Educação, Universidade Federal do Rio Grande do Sul, Porto Alegre, 2010a. Disponível em <http://hdl. handle.net/10183/21380>.

OLIVEIRA, Marcos da Rocha. Gilles Deleuze e o cinema do não. ALEGRAR, Campinas, no $10-$ dez/2012. 
OLIVEIRA, Marcos da Rocha. Notas de leitura para um pesteseller pedagógico. In: CORAZZA, S. M. (Org.). Fantasias de escritura: filosofia, educação, literatura. Porto Alegre: Sulina, 2010b, p. 115-129.

OLIVEIRA, Marcos da Rocha. 10 Passos para dar uma aula escritural. In: CORAZZA, S. M. Didaticário de criação: aula cheia. Porto Alegre: UFRGS, 2012, p.76-79.

OLIVEIRA, Marcos da Rocha. Método de dramatização da aula: o que é a pedagogia, a didática, o currículo? Porto Alegre, 2014. Tese (Doutorado em Educação) - Programa de Pós-Graduação em Educação, Faculdade de Educação, Universidade Federal do Rio Grande do Sul, Porto Alegre, 2014.

TADEU, Tomaz. Um plano de imanência para o currículo. In: TADEU, T.; CORAZZA, S.; ZORDAN, P. Linhas de escrita. Belo Horizonte: Autêntica, 2004, p.127-205.

TADEU, Tomaz. Différen(t/ c) iation: Observações em torno de uma tradução. Porto Alegre, 2005. Texto digitado. 6p.

TAVARES, Gonçalo M. Breves Notas sobre Ciência. Lisboa: Relógio D’Água, 2006.

VALÉRY, Paul. “Meu Fausto” (Esboços). Introdução, tradução e notas de Lídia Fachin e Silvia Maria Azevedo. Cotia: Ateliê Editorial, 2010.

VILA-MATAS, Enrique. História abreviada da literatura portátil. Tradução de Júlio Pimentel Pinto. São Paulo: Cosac Naify, 2011.

ZORDAN, Paola. Geo-educação: arte e paisagens virtuais. In: TADEU, T.; CORAZZA, S.; ZORDAN, P. Linhas de escrita. Belo Horizonte: Autêntica, 2004, p.79-126. 
Marcos da Rocha Oliveira (UFRGS/RS)

Pedagogo, mestre e doutor em Educação pela Universidade Federal do Rio Grande do Sul (UFRGS/RS). Endereço institucional: Faculdade de Educação da UFRGS. Av Paulo Gama, s/n - Bairro Farroupilha. Telefone 33083426. Endereço eletrônico: marqosoliveira@gmail.com

Recebido em: 25/07/2014

Aprovado em: 08/08/2014 